\title{
Time-dependent effect of pneumonectomy on alveolar epithelial fluid clearance in rat lungs
}

Tsutomu Sakuma, MD
Motoyasu Sagawa, MD
Mieko Hida, MS
Yoshihiro Nambu, MD
Kazuhiro Osanai, MD
Hirohisa Toga, MD
Keiji Takahashi, MD
Nobuo Ohya, MD
Michael A. Matthay, MD

From the Departments of Thoracic Surgery $^{\mathrm{a}}$ and Respiratory Medicine, ${ }^{\mathrm{b}} \mathrm{Ka}-$ nazawa Medical University, Uchinada, Ishikawa, Japan, and the Cardiovascular Research Institute, University of California, San Francisco, ${ }^{\text {c }}$ San Francisco, Calif.

This study was supported by a Grant for Collaborative Research from Kanazawa Medical University (S00-13, S01-11) and a Grant-In-Aid for Scientific Research from the Ministry of Education, Science, Sports and Culture of Japan (No. 11670600) and National Institutes of Health grant HL51854.

Received for publication July 27, 2001; revisions requested Nov 19, 2001; revisions received Dec 12, 2001; accepted for publication Dec 14, 2001.

Address for reprints: Tsutomu Sakuma, MD, Thoracic Surgery, Kanazawa Medical University, 1-1 Daigaku, Uchinada, Ishikawa 920-0293, Japan (E-mail: sakumat-t @ kanazawa-med.ac.jp).

J Thorac Cardiovasc Surg 2002;124:668-74

Copyright (C) 2002 by The American Association for Thoracic Surgery

0022-5223/2002 $\$ 35.00+0 \quad \mathbf{1 2 / 1 / 1 2 2 5 4 9}$

doi:10.1067/mtc.2002.122549
Objective: Because pneumonectomy initiates compensatory growth of the remaining lung,we determined the time-dependent effects of pneumonectomy on alveolar fluid clearance capacity.

Methods: Alveolar fluid clearance capacity with the Evans blue-labeled albumin concentration was measured in rats 3 hours, 2 days, 7 days, 14 days, and 28 days after left pneumonectomy. The mechanisms responsible for the increase in alveolar fluid clearance were explored.

Results: Alveolar fluid clearance in the remaining lung was normal through 7 days and then increased 14 and 28 days after pneumonectomy. The increase in alveolar fluid clearance at 28 days after pneumonectomy was accounted primarily by an increase in amiloride-sensitive transport. The expression of epithelial sodium channel messenger RNA was increased in the remaining lung and in type II alveolar epithelial cells isolated from rats 28 days after pneumonectomy. The number of isolated type II cells was larger in pneumonectomized rats than in control rats. Also, $\beta$-adrenergic agonist therapy increased the rate of alveolar fluid clearance at the 3-hour and 28-day time points.

Conclusions: The capacity to remove alveolar fluid in the remaining lung is maintained at a normal level for up to 7 days after pneumonectomy in a rat, and then there is a marked increase in amiloride-sensitive alveolar fluid transport capacity that might depend, at least in part, on increased expression of epithelial sodium channels in type II cells and in part on the increased number of type II cells.

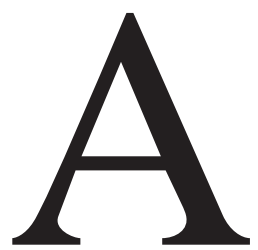

lthough pneumonectomy is a standard method for treatment of bronchogenic carcinoma, postoperative pulmonary edema after pneumonectomy is an important complication. The incidence of postpneumonectomy pulmonary edema is low $(<5 \%)$, but the mortality is high, despite support with supplemental oxygen, positive pressure ventilation, and intensive care support. ${ }^{1,2}$ One of the causes of edema formation was thought to be an increased capillary leak in the remaining lung parenchyma. ${ }^{2}$ An accumulation of interstitial fluid can play an important role in slowing alveolar fluid transport capacity. ${ }^{3}$ Impaired alveolar epithelial fluid transport is associated with a higher mortality and morbidity in patients with pulmonary edema. ${ }^{4,5}$

The initial step in alveolar fluid clearance is an uptake of sodium through apical sodium channels on type II alveolar epithelial cells, coupling with subsequent 
extrusion through basolateral $\mathrm{Na}^{+}-\mathrm{K}^{+}$adenosine triphosphatase. ${ }^{4,6}$ The alveolar water volume follows the osmotic gradient created by transported ions from the alveolar spaces into pulmonary interstitium. ${ }^{4}$ Amiloride inhibits some apical sodium channels, ${ }^{6}$ especially the epithelial sodium channel $(\mathrm{ENaC}) . \beta$-Adrenergic agonists accelerate sodium and fluid transport in in vivo and ex vivo models. ${ }^{4,7,8}$ An important contribution of endogenous catecholamines to alveolar fluid clearance has been reported in rats in septic shock ${ }^{9}$ or in hypovolemic shock ${ }^{10}$ and in dogs with neurogenic pulmonary edema. ${ }^{11}$ In a variety of species, pneumonectomy initiates compensatory growth of the remaining lung in association with the proliferation of type II alveolar epithelial cells. ${ }^{12-18}$ However, it is uncertain whether pneumonectomy affects the function of sodium channels and $\beta_{2}$-adrenoceptors in the remaining lung.

Therefore the first objective in this study was to determine the time course of alveolar fluid clearance in pneumonectomized rats. Because alveolar fluid clearance increased 14 and 28 days after pneumonectomy, the second objective was to determine the mechanisms responsible for the increase in alveolar epithelial fluid transport. To answer this question, we determined whether the increase in alveolar fluid clearance depended on amiloride-sensitive transport and whether there was an increase in the expression of $\alpha$-ENaC mRNA. Also, proliferation of type II alveolar epithelial cells was examined by counting the number of isolated type II cells from the remaining lungs in pneumonectomized rats. Because $\beta$-adrenergic agonists have been shown to increase the resolution of alveolar edema in other models, 7,19,20 as well as perhaps in patients with cardiogenic pulmonary edema, ${ }^{21}$ the third objective was to test the efficacy of $\beta$-adrenergic agonists on stimulating alveolar fluid clearance after a pneumonectomy.

\section{Methods}

\section{General Protocol}

This study was approved by the Animal Care Committee in Kanazawa Medical University. Male Sprague-Dawley rats (200-250 g; Japan SLC Inc, Hamamatsu, Japan) were anesthetized by means of intraperitoneal administration of pentobarbital sodium $(50 \mathrm{mg} /$ $\mathrm{kg}$ ). A flexible 16-gauge intravenous polyethylene catheter was inserted periorally, and the rats were ventilated with a rodent ventilator (Model 683; Harvard Apparatus, South Natick, Mass) at a constant tidal volume $(7 \mathrm{~mL} / \mathrm{kg})$ with air in the presence of positive end-expiratory pressure $\left(2 \mathrm{~cm} \mathrm{H}_{2} \mathrm{O}\right)$. In the right lateral decubitus position, skin of the left thorax was sterilized, and the left thorax was opened through the fourth intercostal space. The left hilum was ligated with a silk suture, and then left pneumonectomy was carried out. The thorax was closed with a nylon suture. The entire procedure took approximately 15 minutes. The rats were extubated within 30 minutes after left pneumonectomy and allowed access to food and water ad libitum.

We isolated the right lungs from rats that had undergone left pneumonectomy and measured alveolar fluid clearance in the absence of either pulmonary perfusion or ventilation, as previously reported. ${ }^{22-24}$ Briefly, rats were anesthetized by means of intraperitoneal administration of pentobarbital sodium $(50 \mathrm{mg} / \mathrm{kg})$. An endotracheal tube was inserted through a tracheostomy. Blood samples were obtained from the abdominal aorta for the measurement of plasma catecholamine levels, and then rats were exsanguinated. Through a median sternotomy, the trachea, the right lung, and the heart were excised en bloc. The lungs were wrapped in Saran Wrap to prevent dehydration and were placed in a humidified incubator at $37^{\circ} \mathrm{C}$. A warmed physiologic saline solution $(0.7 \mathrm{~mL} / \mathrm{kg})$ containing $5 \%$ bovine albumin and Evans blue dye $(0.1 \mathrm{mg} / \mathrm{mL})$ was instilled into the isolated lungs followed by $2 \mathrm{~mL}$ of oxygen to deliver all of the instilled fluid into the distal airspaces. The lungs were inflated with $100 \%$ oxygen at an airway pressure of $7 \mathrm{~cm} \mathrm{H}_{2} \mathrm{O}$. Alveolar fluid was aspirated 1 hour after instillation. The concentrations of Evans blue-labeled albumin in the instilled and aspirated solutions were measured with a spectrophotometer at a wavelength of $621 \mathrm{~nm}$ (BioSpec-1600; Shimadzu, Kyoto, Japan).

Alveolar fluid clearance. Alveolar fluid clearance was estimated by measuring the increase in the concentrations of alveolar Evans blue-labeled albumin. ${ }^{22-24}$ Alveolar fluid clearance (AFC) was calculated as follows:

$$
\mathrm{AFC}=[(\mathrm{Vi}-\mathrm{Vf}) / \mathrm{Vi}] \times 100,
$$

where $\mathrm{V}$ is the volume of the instilled albumin solution (i) and the final alveolar fluid (f). Final alveolar fluid volume (Vf) was calculated as follows:

$$
\mathrm{Vf}=(\mathrm{Vi} \times \mathrm{EBi}) / \mathrm{EBf}
$$

where EB is the concentration of Evans blue-labeled albumin in the instilled albumin solution (i) and the final alveolar fluid (f).

By using trichloroacetic acid, greater than $99.5 \%$ of Evans blue dye was bound to albumin in the instilled and aspirated solutions. ${ }^{23}$

Plasma catecholamine levels. Blood samples were obtained from the abdominal aorta and transferred immediately to chilled tubes containing $0.02 \mathrm{~mL}$ of heparin sodium. The blood samples were then centrifuged $\left(1200 \mathrm{~g}\right.$ for 10 minutes at $\left.4^{\circ} \mathrm{C}\right)$, and the plasma samples were stored at $-80^{\circ} \mathrm{C}$. Plasma catecholamine levels (epinephrine, norepinephrine, and dopamine) were measured by means of high-performance liquid chromatography with a trihydroxyindole reaction. ${ }^{24}$

RNA isolation. Total RNA was extracted from perfused rat whole lungs and isolated in type II alveolar epithelial cells by using an RNA isolation kit (Trizol; Gibco BRL, Life Technologies, Rockville, Md). Type II alveolar epithelial cells were isolated from rats 28 days after pneumonectomy. The rat lungs were digested with pancreatic elastase, followed by centrifugation over a discontinuous metrizamide density gradient. ${ }^{23}$ The purity of freshly isolated type II cell preparations was $72.4 \%$. When the type II cells were plated for 24 hours, the purity was greater than $95 \%$. The amount of tritiated thymidine uptake was maintained when the cells were plated for 72 hours. ${ }^{23}$

Semiquantitative reverse transcription-polymerase chain reaction. DNase I (a RQ1 RNase-free Dnase; Promega, Madison, Wis) was added to the total RNA sample and incubated at $37^{\circ} \mathrm{C}$ for 15 minutes. The reaction mixture was extracted with phenol/ chloroform, and RNA was precipitated with methanol. First-strand 
DNA was synthesized with random hexamer primers by using a reverse transcriptase (Superscript RT, Gibco BRL). RNase H (Gibco BRL) was added. Designated primers, Taq DNA polymerase (Takara Ex Taq; Takara, Shiga, Japan), and other reaction mixtures were added. The polymerase chain reaction (PCR) was started for 22 cycles at $94^{\circ} \mathrm{C}$ for 30 seconds, $55^{\circ} \mathrm{C}$ for 30 seconds, and $72^{\circ} \mathrm{C}$ for 90 seconds by using a thermal cycler (Gene Amp PCR system 2400; Perkin Elmer, Norwalk, Conn). Aliquots of the PCR product were electrophoresed with $2 \%$ agarose gel and stained with ethidium bromide. Primers were 5'-ACGCCTCCAACTCGCCTAAG-3' and 5'-GCCACAGCACCGCCCAGAAG-3' for $\alpha$-rENaC. Primers for glyceraldehide-3-phosphate dehydrogenase, used as controls, were 5'-ACCCAGAAGACTGT-

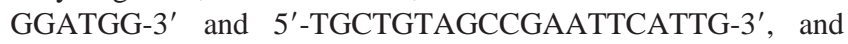
PCR was started from $94^{\circ} \mathrm{C}$ for 16 cycles. The band of $\alpha$-ENaC mRNA was normalized to the density of the glyceraldehide-3phosphate dehydrogenase band.

Dry lung weight and protein content. For the measurement of dry lung weight and protein content, the pulmonary artery was flushed with a warmed phosphate buffer solution to remove blood in the pulmonary vessels. The dry lung weight of the right lung was measured by drying the lungs to a constant weight at $70^{\circ} \mathrm{C}$ for 48 hours. The protein concentrations in the supernatant of the homogenized right lungs were measured with a spectrophotometer at a wavelength of $281 \mathrm{~nm}$ (BioSpec-1600; Shimadzu, Kyoto, Japan). Total content of protein was calculated by multiplying the total volume of homogenized lungs.

\section{Specific Protocol}

Group 1: Time course of alveolar fluid clearance $(n=43)$. We measured alveolar fluid clearance and plasma catecholamine levels in rats 3 hours $(n=4), 2$ days $(n=4), 7$ days $(n=4), 14$ days $(n=6)$, and 28 days $(n=6)$ after pneumonectomy. As a control, the measurement was carried out on 7 rats immediately after left pneumonectomy. Sham thoracotomy in the absence of the lung resection was performed to determine the effect of thoracotomy, and alveolar fluid clearance was measured 28 days after thoracotomy $(\mathrm{n}=8)$. In addition, Alveolar fluid clearance was measured 28 days after anesthesia in the absence of thoracotomy to determine the effect of anesthesia and ventilation $(n=4)$.

Group 2: Effect of amiloride on alveolar fluid clearance after pneumonectomy $(n=8)$. To determine the mechanisms responsible for the increase in alveolar fluid clearance 28 days after pneumonectomy, we tested the hypothesis that the fraction of amiloride-sensitive alveolar fluid clearance increased in pneumonectomized rats. An albumin solution in the presence of $5 \times 10^{-4}$ $\mathrm{mol} / \mathrm{L}$ amiloride, a sodium channel inhibitor, was instilled into the right lungs isolated from control rats $(n=4)$ and from rats 28 days after pneumonectomy $(\mathrm{n}=4)$.

Group 3: Expression of $\alpha-E N a C$ in the lung and type II alveolar epithelial cells. Because the amiloride-sensitive fraction increased in pneumonectomized rats, the expression of $\alpha$-ENaC mRNA was measured in the right lung tissue from 4 rats and in the isolated type II alveolar epithelial cells from 4 rats 28 days after pneumonectomy. As controls, the expression of $\alpha$-ENaC mRNA was measured in the right lung tissue from 4 rats and in the isolated type II alveolar epithelial cells from rats in the absence of pneumonectomy.
Group 4: Proliferation of type II alveolar epithelial cells $(n=$ 16). To determine whether the proliferation of type II cells increased alveolar fluid clearance in pneumonectomized rats, the proliferation was morphologically examined in the right lungs excised from rats 28 days after pneumonectomy $(n=4)$ and from normal rats without treatment of left pneumonectomy $(n=4)$. The excised lungs were instilled with $10 \%$ buffered formalin solution gently through a tracheal tube. The trachea was ligated with a silk suture, and then the lungs were placed in $10 \%$ buffered formalin solution until the slices of the lungs were paraffin embedded, thin sectioned, and stained with hematoxylin and eosin. The proliferation of the type II cells was examined in the stained specimens by light microscopy. In addition, total numbers of type II alveolar epithelial cells isolated from the right lungs were counted in rats 28 days after pneumonectomy $(\mathrm{n}=4)$ and in age-matched normal rats $(\mathrm{n}=4)$.

Group 5: Effect of terbutaline on alveolar fluid clearance after pneumonectomy $(n=8)$. Although alveolar fluid clearance did not increase 3 hours after pneumonectomy, plasma epinephrine levels increased at that time. Therefore we determined whether the remaining lungs were responsive to a $\beta_{2}$-adrenergic agonist. An albumin solution in the presence of $10^{-5} \mathrm{~mol} / \mathrm{L}$ terbutaline was instilled into the right lungs in rats 3 hours $(\mathrm{n}=4)$ and 28 days $(\mathrm{n}=4)$ after pneumonectomy.

\section{Statistics}

Data are summarized as means and SD. The data were analyzed by means of 1-way analysis of variance with a Student-NewmanKeuls post hoc test when multiple comparisons were needed. When comparisons were made between 2 experimental groups, an unpaired Student $t$ test was used.

\section{Results}

The studies were organized to initially measure alveolar fluid clearance at selected time periods after pneumonectomy and then to further evaluate the mechanisms responsible for the change in the rate of alveolar fluid transport over a 28-day period.

\section{Time Course of Alveolar Fluid Clearance in Rats After Left Pneumonectomy}

Alveolar fluid clearance capacity was maintained for 7 days after pneumonectomy and then improved 14 and 28 days after pneumonectomy. Alveolar fluid clearance in the remaining right lungs was $21 \% \pm 2 \%$ immediately after left pneumonectomy and did not significantly change over the first 7 days after left pneumonectomy (Figure 1). However, alveolar fluid clearance increased by $47 \%$ and $43 \%$ at 14 and 28 days after pneumonectomy, respectively (Figure 1). Anesthesia or thoracotomy in the absence of pneumonectomy had no effect on alveolar fluid clearance 28 days after pneumonectomy (Figure 2). Although plasma epinephrine levels increased minimally but significantly 3 hours after left pneumonectomy, the levels returned to control levels from 2 to 28 days after pneumonectomy (Table 1). Plasma 


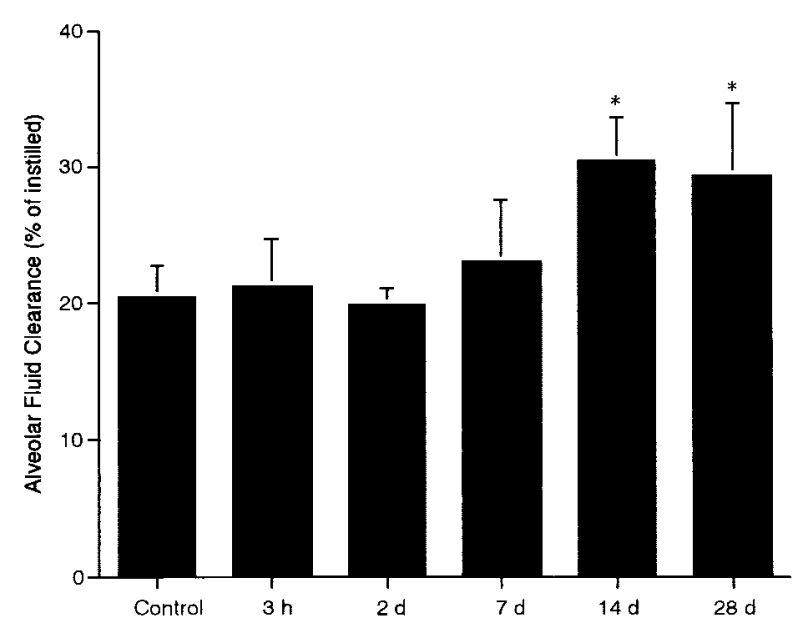

Figure 1. Time course of alveolar fluid clearance in the remaining right lungs in pneumonectomized rats. Alveolar fluid clearance significantly increased 14 and 28 days after pneumonectomy. ${ }^{*} \boldsymbol{P}<.05$ versus control rat.

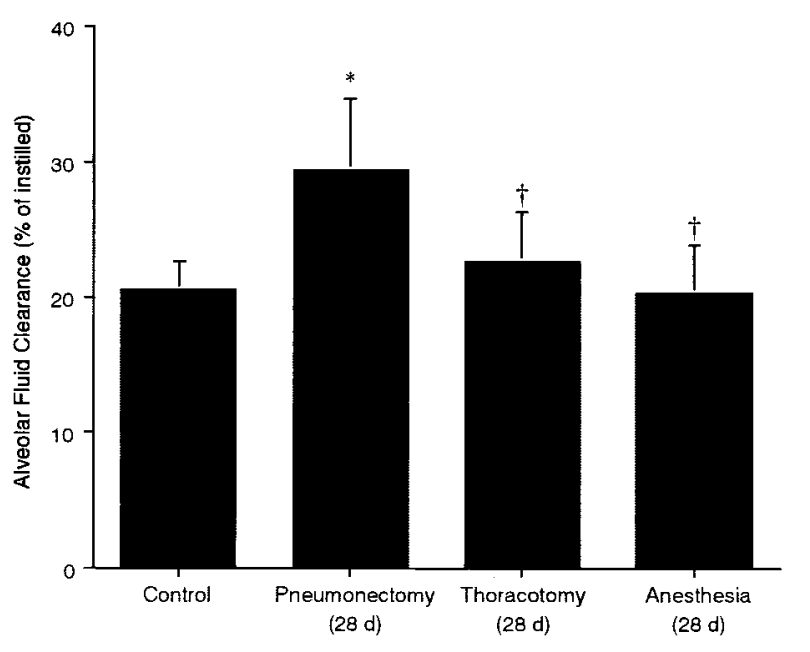

Figure 2. Pneumonectomy increased alveolar fluid clearance. Sham thoracotomy and anesthesia did not change alveolar fluid clearance. ${ }^{*} P<.05$ versus control rat; $+P<.05$ versus pneumonectomy.

TABLE 1. Plasma catecholamine levels in rats after left pneumonectomy

\begin{tabular}{|c|c|c|c|c|c|c|}
\hline Catecholamines & Control & $3 \mathrm{~h}$ & $2 \mathrm{~d}$ & $7 \mathrm{~d}$ & $14 \mathrm{~d}$ & $28 \mathrm{~d}$ \\
\hline Epinephrine $(\mathrm{pg} / \mathrm{mL})$ & $155 \pm 57$ & $482 \pm 221^{*}$ & $265 \pm 93$ & $231 \pm 92$ & $191 \pm 75$ & $170 \pm 63$ \\
\hline Norepinephrine $(\mathrm{pg} / \mathrm{mL})$ & $356 \pm 105$ & $298 \pm 152$ & $273 \pm 63$ & $260 \pm 67$ & $224 \pm 52$ & $253 \pm 72$ \\
\hline Dopamine $(\mathrm{pg} / \mathrm{mL})$ & $111 \pm 96$ & $121 \pm 116$ & $122 \pm 83$ & $50 \pm 10$ & $65 \pm 27$ & $90 \pm 55$ \\
\hline
\end{tabular}

${ }^{*} P<.05$ versus control levels.

norepinephrine and dopamine levels did not significantly change in pneumonectomized rats.

Amiloride-sensitive Alveolar Fluid Clearance in Rats After Pneumonectomy

Pneumonectomy increased the amiloride-sensitive fraction in alveolar fluid clearance. Amiloride inhibited alveolar fluid clearance by $64 \%$ in control rats immediately after pneumonectomy (Figure 3). Because alveolar fluid clearance in the presence of amiloride was similar in control rats and in rats 28 days after pneumonectomy (Figure 3), the increase in alveolar fluid clearance was entirely in the amiloride-sensitive fraction.

\section{Expression of $\alpha$-ENaC in the Lung Tissue and Type II} Alveolar Epithelial Cells

Pneumonectomy induced upregulation of $\alpha$-ENaC mRNA and lung growth in the remaining lungs. Dry lung weight and protein content increased in the right lungs in rats 28 days after pneumonectomy (Figure 4). The semiquantitative ratios of $\alpha$-ENaC mRNA to G3PDH mRNA increased both in whole lung tissue and in isolated type II cells (Figure 4).

\section{Proliferation of Type II Alveolar Epithelial Cells}

There was no morphologic evidence of type II alveolar epithelial cell proliferation in the remaining right lung in rats 28 days after pneumonectomy. However, the total number of isolated alveolar epithelial type II cells from rats 28 days after pneumonectomy was greater than that from the right lungs in control rats $(26.6 \pm 7.6$ million in pneumonectomized rats and $18.2 \pm 3.1$ million in control rats, $P<$ $.05)$.

Effect of Terbutaline on Alveolar Fluid Clearance after Pneumonectomy

The remaining lungs after pneumonectomy were responsive to terbutaline, a $\beta_{2}$-adrenergic agonist. Terbutaline significantly increased alveolar fluid clearance by $38 \%$ in control rats (Figure 5). Similarly, terbutaline increased alveolar fluid clearance by $38 \%$ in rats 28 days after pneumonectomy (Figure 5).

\section{Discussion}

The most important finding in this study is that alveolar fluid clearance in the remaining lung did not change over 7 days after pneumonectomy but then increased by nearly $50 \%$ at 14 and 28 days after pneumonectomy. Because alveolar fluid clearance did not increase in sham-operated and anesthetized rats in the absence of thoracotomy, it is likely that pneumonectomy itself induced the increase in alveolar epithelial fluid transport in pneumonectomized rats. 


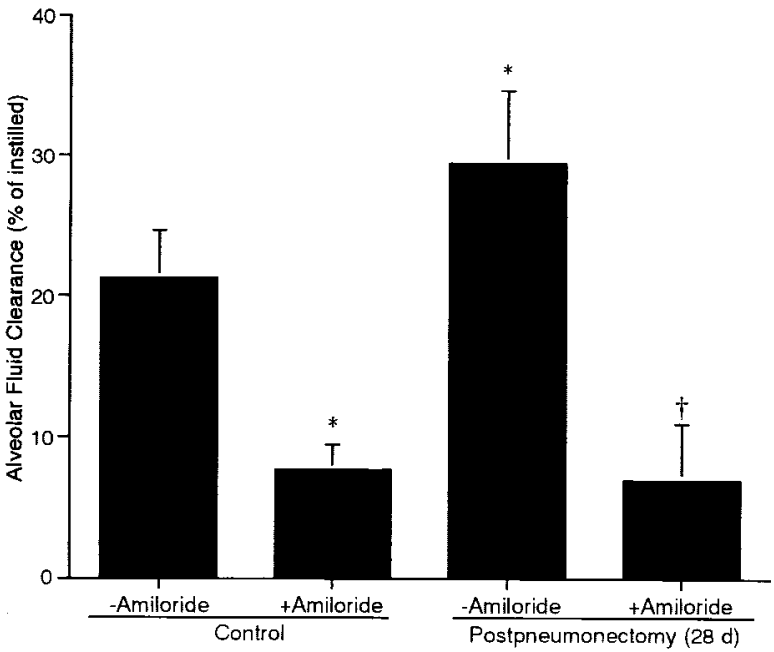

Figure 3. Effect of amiloride on alveolar fluid clearance 28 days after pneumonectomy. ${ }^{*} \boldsymbol{P}<.05$ versus $(-$ )amiloride control rat; $\dagger P<.05$ versus $(-$ amiloride 28 days after pneumonectomy.

We tested 4 hypotheses to account for the increase in alveolar fluid clearance in pneumonectomized rats. Because elevation of endogenous plasma catecholamine levels can increase alveolar fluid clearance, ${ }^{9-11}$ the first hypothesis was that endogenous catecholamines would increase alveolar fluid clearance in the remaining lungs in pneumonectomized rats. We sequentially measured plasma catecholamine levels for up to 28 days after left pneumonectomy. Epinephrine levels significantly increased 3 days after pneumonectomy, but the elevation was minimal and inconsistent with the increase in alveolar fluid clearance. In addition, alveolar fluid clearance increased 14 and 28 days after pneumonectomy when plasma epinephrine levels were normal. Therefore it is unlikely that plasma catecholamines played a primary role in the increase in alveolar fluid clearance in pneumonectomized rats.

The second hypothesis was that proliferation of type II alveolar epithelial cells after pneumonectomy played a role in the increase in alveolar fluid clearance in pneumonectomized rats. Some prior reports have indicated that there was an increase in the number of alveolar type II cells after pneumonectomy in rats. ${ }^{12}$ We previously reported that the proliferation of type II cells increased alveolar fluid clearance in the remaining human lungs after lobectomy for bronchogenic carcinoma. ${ }^{13}$ However, proliferation of type II cells was not identified with light microscopy in this study. Because light microscopy has a limitation in the quantitative evaluation of the type II cell proliferation, we isolated type II alveolar cells and compared the number of type II cells that could be isolated from the lungs in pneumonectomized rats and from the control lungs. The total number of isolated type II cells was greater in pneumonec-
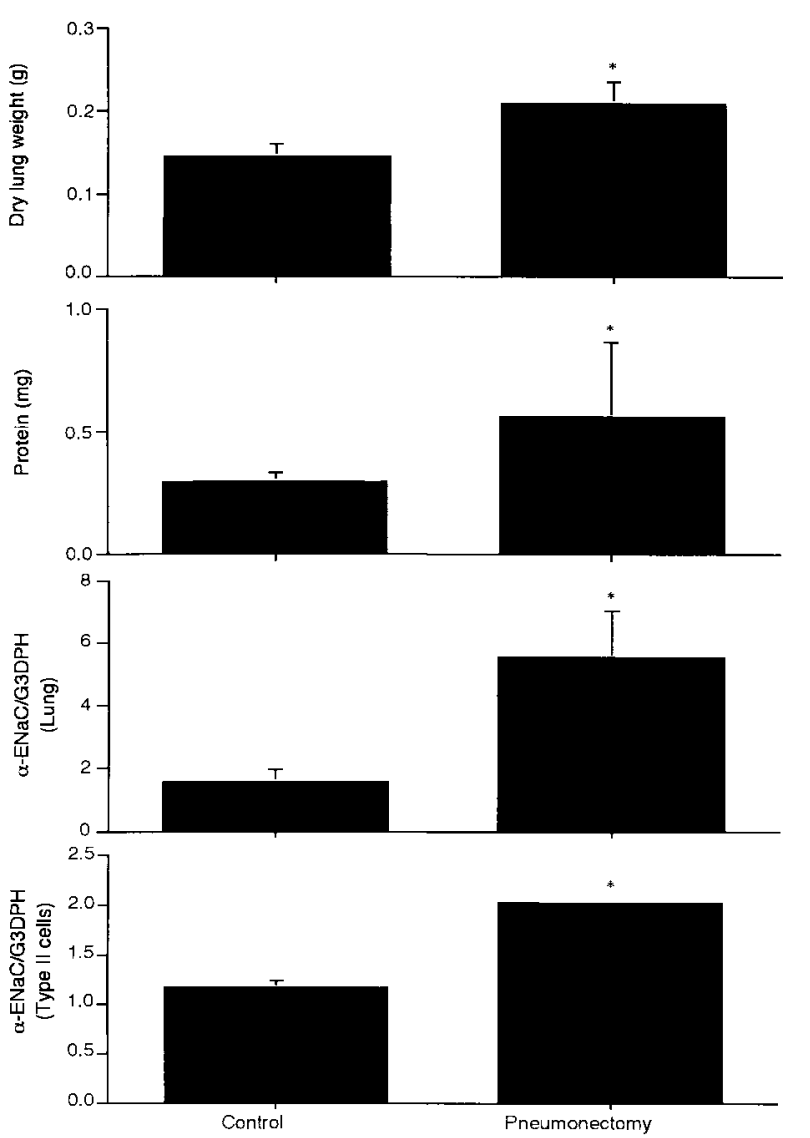

Figure 4. Dry lung weight, protein content, and expression of $\alpha$-ENaC were increased in pneumonectomized rats. ${ }^{*} P<.05$ versus corresponding control rats.

tomized rats than in normal rats. There was no difference between the purity of type II cells isolated from pneumonectomized rats compared with those from normal rats. Therefore it is probable that proliferation of type II cells played a role, in part, in the enhanced alveolar fluid clearance observed in this study.

The third hypothesis was that the surface area of alveolar epithelial cells increased in pneumonectomized rats ${ }^{14,15}$ and resulted in increased alveolar fluid clearance. Accelerated lung growth continues in a linear fashion until normal total lung mass is achieved 14 days after pneumonectomy. ${ }^{16}$ The compensatory lung growth is consistent with a previous report in which surface area increased in association with the lung growth that reached to that of both lungs 14 days after pneumonectomy. ${ }^{15}$ However, it is unlikely that the increase in surface area in pneumonectomized rats played a primary role in these studies. First, although we instilled the albumin solution into the right lung in this study, basal alveolar fluid clearance was not different from that in rats with instillation of the albumin solution into both lungs. ${ }^{23}$ Second, alveolar fluid clearance in older rats with larger 
lungs was not different from alveolar fluid clearance in pneumonectomized rats. ${ }^{22-24}$ Third, we previously instilled different volumes of the albumin solutions, ranging from 2 to $6 \mathrm{~mL} / \mathrm{kg}$ body weight, indicating that alveolar surface area into which the albumin solution was instilled might be different, but alveolar fluid clearance was independent of instilled volume of the albumin solution. ${ }^{4}$

The final hypothesis was that the function of sodium channel played a primary role in the increase in alveolar fluid clearance in pneumonectomized rats. To test this hypothesis, we administered amiloride, a sodium channel inhibitor, into the rat lungs immediately and 28 days after pneumonectomy and found that only amiloride-sensitive alveolar fluid clearance increased 28 days after pneumonectomy. In addition, we determined whether the synthesis of $\alpha$-ENaC mRNA increased in pneumonectomized rats and found that $\alpha$-ENaC mRNA expression was upregulated in both whole lung tissue and isolated type II cells. The upregulation of RNA and DNA after pneumonectomy ${ }^{17}$ supports the possibility of sodium channel upregulation. Therefore it is likely that the function of sodium channels might be upregulated in alveolar epithelial cells after pneumonectomy. Upregulation of sodium channel might explain the mechanism for the improvement of alveolar fluid clearance in the absence of type II cell proliferation by means of light microscopic examination.

The upregulation of amiloride-sensitive alveolar fluid clearance has been reported in rat lungs that responded to several stimuli: endotoxin, keratinocyte growth factor, transforming growth factor $\alpha$, and $\beta$-adrenergic agonists. ${ }^{4}$ In addition, several factors have been implicated in compensatory lung growth: postoperative changes in tissue inflation, elevated blood flow in the residual pulmonary vasculature, intraoperative or perioperative hypoxemia, and circulating or soluble factors by endocrine, paracrine, or autocrine mechanisms. ${ }^{24}$ Further studies are needed to identify the factors that upregulated sodium channel expression in pneumonectomized rats.

Increased blood flow, endothelial damage with increased permeability, and inability of the lymphatics to transport interstitial fluid occur in the remaining lung early after pneumonectomy. ${ }^{2}$ An accumulation of interstitial fluid can reduce alveolar fluid transport capacity. ${ }^{3}$ Because alveolar fluid clearance increased late after pneumonectomy in this study, it is possible that the improvement of capillary leak and lymphatic drainage played a role in the increase in alveolar fluid clearance.

Because elevated plasma epinephrine levels 3 hours after pneumonectomy did not increase alveolar fluid clearance, we determined whether the remaining lungs in pneumonectomized rats were insensitive to an exogenous $\beta_{2}$-adrenergic agonist. We administered terbutaline, a selective $\beta_{2}$-adrenergic agonist, which has been commonly used to determine

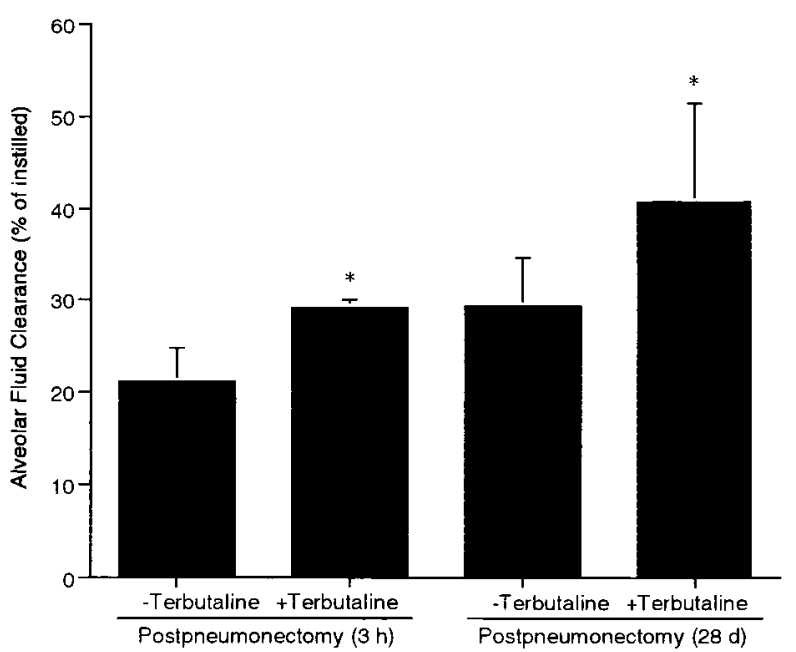

Figure 5. Effects of terbutaline on alveolar fluid clearance. Terbutaline increased alveolar fluid clearance in rats 28 days after pneumonectomy, as well as in rats $\mathbf{3}$ hours after pneumonectomy. ${ }^{*} \boldsymbol{P}<.05$ versus corresponding alveolar fluid clearance.

the effect of $\beta_{2}$-adrenergic agonist on alveolar fluid clearance in in vivo and ex vivo rat lungs ${ }^{22,25,26}$ and in cultured type II alveolar epithelial cells from rat lungs. ${ }^{27,28}$ Terbutaline increased alveolar fluid clearance in the remaining lungs 3 hours after pneumonectomy. The increased rates seemed to be maximal because the rates were similar to the peak rate that was observed in a dose-response relationship. ${ }^{29}$ Therefore the $\beta_{2}$-adrenoceptors were normally responsive to terbutaline, and the results suggest that the plasma epinephrine levels 3 hours after pneumonectomy were insufficient to increase alveolar fluid clearance in pneumonectomized rats.

This study was carried out in the lungs in the absence of lung injury. Although the response to amiloride and $\beta_{2}$ adrenergic agonist is preserved in moderately injured lungs, $, 4,9,10,13$ further studies are necessary to determine whether the remaining lungs in the presence of pulmonary edema after pneumonectomy are able to respond to such agents.

In summary, alveolar fluid clearance is preserved in the remaining right lung for 7 days and then improves at 14 and 28 days after pneumonectomy in rats. Both an upregulation of amiloride-sensitive sodium channels and an increase in the number of alveolar type II cells are responsible for the increase in alveolar fluid clearance. $\beta_{2}$-Adrenergic stimulation is capable of further upregulating alveolar fluid clearance at all time points after pneumonectomy. The time course of alveolar fluid clearance and responsiveness to a $\beta_{2}$-adrenergic agonist suggest that the capacity to recover from postpneumonectomy pulmonary edema might be maintained after lung resection. 


\section{References}

1. Verheijen-Breemhaar L, Bogaard JM, van den Berg B, Hilvering C. Postpneumonectomy pulmonary oedema. Thorax. 1988;43:323-26.

2. Deslauriers J, Aucoin A, Gregoire J. Postpneumonectomy pulmonary edema. Chest Surg Clin North Am. 1998;8:611-31.

3. Fukuda N, Folkesson HG, Matthay MA. Relationship of interstitial fluid volume to alveolar fluid clearance in mice: ventilated vs. in situ studies. J Appl Physiol. 2000;89:672-9.

4. Matthay MA, Folkesson HG, Verkman AS. Salt and water transport across alveolar and distal airway epithelia in the adult lung. Am J Physiol. 1996;270:L487-503.

5. Ware LB, Matthay MA. Alveolar fluid clearance is impaired in the majority of patients with acute lung injury and the acute respiratory distress syndrome. Am J Respir Crit Care Med. 2001;163:1376-83.

6. Matalon S, Benos DJ, Jackson RM. Biophysical and molecular properties of amiloride-inhibitable $\mathrm{Na}^{+}$channels in alveolar epithelial cells. Am J Physiol. 1996;271:L1-22.

7. Berthiaume Y, Staub NC, Matthay MA. Beta-adrenergic agonists increase lung liquid clearance in anesthetized sheep. J Clin Invest. 1987;79:335-43

8. Sakuma T, Okaniwa G, Nakada T, Nishimura T, Fujimura S, Matthay MA. Alveolar fluid clearance in the resected human lung. Am J Respir Crit Care Med. 1994;150:305-10.

9. Pittet JF, Wiener-Kronish JP, McElroy MC, Folkesson HG, Matthay MA. Stimulation of lung epithelial liquid clearance by endogenous release of catecholamines in septic shock in anesthetized rats. $J$ Clin Invest. 1994;94:663-71.

10. Modelska K, Matthay MA, McElroy MC, Pittet JF. Upregulation of alveolar fluid clearance after fluid resuscitation for hemorrhagic shock in rats. Am J Physiol. 1997;273:L305-14.

11. Lane SM, Maender KC, Awender NE, Maron MB. Adrenal epinephrine increases alveolar liquid clearance in a canine model of neurogenic pulmonary edema. Am J Respir Crit Care Med. 1998;158:760-8.

12. Thet LA, Law DJ. Changes in cell number and lung morphology during early postpneumonectomy lung growth. J Appl Physiol. 1984; 56:975-8.

13. Sakuma T, Usuda K, Handa M, Okaniwa G, Nakada T, Fujimura S, et al. Increased alveolar fluid clearance following thoracotomy: report of a case and results of an analysis. Surg Today. 1997;27:762-5.

14. Cagle PT, Thurlbeck WM. Postpneumonectomy compensatory lung growth. Am Rev Respir Dis. 1988;138:1314-26.

15. Rannels DE, Stockstill B, Mercer RR, Crapo JD. Cellular changes in the lungs of adrenalectomized rats following left pneumonectomy. Am J Respir Cell Mol Biol. 1991;5:351-62.
16. Rannels DE, Burkhart LR, Watkins CA. Effect of age on the accumulation of lung protein following unilateral pneumonectomy in rats. Growth. 1984;48:297-308.

17. Rannels DE, White DM, Watkins CA. Rapidity of compensatory lung growth following pneumonectomy in adult rats. J Appl Physiol. 1979; 46:326-33.

18. Rannels DE, Rannels SR. Compensatory growth of the lung following partial pneumonectomy. Exp Lung Res. 1988;14:157-82.

19. Frank JA, Wang Y, Osorio O, Matthay MA. $\beta$-Adrenergic agonist therapy accelerates the resolution of hydrostatic pulmonary edema in sheep and rats. J Appl Physiol. 2000;89:1255-65.

20. Saldías FJ, Comellas A, Ridge KM, Lecuona E, Sznajder JI. Isoproterenol improves ability of lung to clear edema in rats exposed to hyperoxia. J Appl Physiol. 1999;87:30-5.

21. Verghese GM, Ware LB, Matthay BA, Matthay MA. Alveolar epithelial fluid transport and the resolution of clinically severe hydrostatic pulmonary edema. J Appl Physiol. 1999;87:1301-12.

22. Sakuma T, Folkesson HG, Suzuki S, Okaniwa G, Nakada T, Fujimura $\mathrm{S}$, et al. Beta-adrenergic agonist stimulated alveolar fluid clearance in ex vivo human and rat lungs. Am J Respir Crit Care Med. 1997;155: 506-12.

23. Sakuma T, Tuchihara $C$, Ishigaki M, Osanai K, Nambu Y, Toga H, et al. Denopamine, a $\beta_{1}$-adrenergic agonist, increases alveolar fluid clearance in ex vivo rat and guinea pig lungs. J Appl Physiol. 2001; 90:10-16.

24. Sakuma T, Hida M, Nambu Y, Osanai K, Toga H, Takahashi K, et al. Beta1-adrenergic agonist is a potent stimulator of alveolar fluid clearance in hyperoxic rat lungs. Jpn J Pharmacol. 2001;85:161-6.

25. Jayr C, Garat C, Meignan M, Pittet JF, Zelter M, Matthay MA. Alveolar liquid and protein clearance in anesthetized ventilated rats. J Appl Physiol. 1994;76:2636-42.

26. Lasnier JM, Wangensteen OD, Schmitz LS, Gross CR, Ingbar DH. Terbutaline stimulates alveolar fluid reabsorption in hypoxic lung injury. J Appl Physiol. 1996;81:1723-9.

27. Goodman BE, Brown SES, Crandall ED. Regulation of transport across pulmonary alveolar epithelial cell monolayers. J Appl Physiol. 1984;57:703-10.

28. Yue G, Shoemaker RL, Matalon S. Regulation of low-amilorideaffinity sodium channels in alveolar type II cells. Am J Physiol. 1994;267:L94-00.

29. Sakuma T, Tuchihara C, Ishigaki M, Osanai K, Nambu Y, Toga H, et al. Beta ${ }_{1}$-adrenoceptor stimulation by high-dose terbutaline downregulates terbutaline-stimulated alveolar fluid clearance in ex vivo rat lung. Exp Lung Res. 2001;27:453-68. 